\title{
The Utilization of Escherichia Coli-based Magnetic Nanobeads as An Ultrasensitive Biosensor for Mercucy
}

\author{
Sun Ying \\ Key Lab of Liaoning Colleges of E\&M Automation, Shenyang University, Shenyang, China
}

\begin{abstract}
It is an arduous task to detect the traces of heavy metals in real environmental samples. In this paper, the use of micro-organisms as bioreceptors and the merits of nanobeads' (NBs) properties are combined to develop a novel electrochemical biosensor based on nanocomposite films. The whole Escherichia. coli cells were fixed onto a surface of indium-tin-oxide glass with and without NBs and/or polyelectrolyte multilayers. In addition, the electrochemical impedance spectroscopy technique, mercury was used to detect.
\end{abstract}

Index Terms: Escherichia Coli; Biosensor; nanobeads; polyelectrolyte multilayers; Mercucy

(C) 2011 Published by MECS Publisher. Selection and/or peer review under responsibility of the Research Association of Modern Education and Computer Science.

\section{Introduction}

Heavy metals are natural components of the Earth's crust. They cannot be degraded or destroyed. To a small extent they enter our bodies via food, drinking water and air [1,2]. At higher concentrations they can lead to poisoning because they tend to bioaccumulate [3]. The detection is restricted because of the extremely low concentrations. In recent years, the whole-cell biosensors have been used to replace other old complicated and costly methods.

In this work, nanocomposite film which fixes up the whole cells is adsorbed onto indium-tin-oxide (ITO) glass as work electrode to form the biosensor system. The proposed biosensor shows sensitive electrochemical responses to mercury. Four membranes elaborated on the work electrode surfaces are compared to analyze the performances of the biosensor: bacteria are deposited directly on the electrode surface (ITO-bacteria), bacteria deposited on nanobeads polyelectrolyte multilayers functionalized electrode (ITO-(PEM)3- bacteria), bacteria deposited on electrode surface (ITO-NBs-bacteria), and bacteria deposited on NBs functionalized PEM electrode surface (ITO-NBs-(PEM)3- bacteria).

* Corresponding author.

E-mail address: yingsun1215@foxmail.com 


\section{Materials and methods}

\section{A. Chemicals}

The nanobead sizes were in the 10-20 $\mathrm{nm}$ range, and the nanobeads were suspended in ultrapure water (milliQ) with a resistance about $18.0 \mathrm{M} \Omega . \mathrm{cm}-1$, initially filtered through a $0.45 \mu \mathrm{m}$ millipore filter, to obtain $1 \% \mathrm{w} / \mathrm{w}$ stock suspension. The used Polyelectrolytes (PE) are poly(allylamine hydrochlorure) (PAH, cation) and poly(styrene sulfonate) (PSS, anion). Stock solution (1g.L-1) of $\mathrm{Hg} 2+$ was prepared from $\mathrm{Hg}(\mathrm{NO}) 2 . \mathrm{H} 2 \mathrm{O}$ in PBS.

B. Electrical impedance spectroscopy

Electrical impedance spectroscopy (EIS) analysis, based on the interaction of an electrical current applied at different frequencies and the response of the biophysical compartments is of great interest for investigating these topics. The electrochemical system consists of three electrode-electrochemical cell and a potentiostat connected to a PC computer [4]. The used electrodes are the working, the reference and the auxiliary or the counter electrode. The reference electrode is a saturated calomel electrode $\mathrm{Hg} / \mathrm{Hg} 2 \mathrm{Cl} 2 / \mathrm{KCl}$ (sat) one. The counter electrode is a platinum metal while the working electrode is a semiconducting indium-tin-oxide (ITO) glass. Before using the ITO electrodes, they were carefully cleaned by successive ultra sonications in different solvents. Firstly, the electrodes were sonicated in acetone for $15 \mathrm{~min}$ then in ethanol for $15 \mathrm{~min}$. Each sonication step was followed by rinsing the samples two or three times with $\mathrm{H} 2 \mathrm{O}$ and dried with nitrogen flow.

The method consists in applying to the electrochemical system under study a sinusoidal AC interfacial potential $\mathrm{V}(\omega, \mathrm{t})$ and measuring the resulting current response $\mathrm{I}(\omega, \mathrm{t})$ flowing through the system. The ratio of the applied voltage to the measured current is the impedance of the system which is easily calculated over a wide frequency range. The impedance spectra are obtained by sequential measurements of $V(\omega, t)$ and I $(\omega, t)$ for each single frequency that contributes to the spectrum. The measurement data can be presented in Nyquist plot in which the imaginary impedance Zim $(\omega)$ is plotted versus the real impedance Zreal $(\omega)$. The impedance spectra were realized for thin polyelectrolyte multilayer films (PEM) deposited on the ITO working electrode [5].

$$
\mathrm{Z}=\text { Zreal }+\mathrm{j} \text { Zim }
$$

\section{Results and discussion}

A. Impedimetric monitoring of bacteria deposited on ITO-bacteria and ITO-NBs-bacteria

The impedance spectra of ITO and ITO-NBs bacteria was shown in Fig. 1 and Fig. 2 with the concentrations ranging from 10-12 $\mathrm{M}$ to $10-4 \mathrm{M}$. It was observed that the detection limit was 10-10 $\mathrm{M}$ for mercury metal if immobilized bacteria on ITO without nanobeads (ITO-bacteria) was used (Fig. 1), while the detection limit was deceased to 10-12 M for ITO with nanobeads (ITO-NBs-bacteria) (Fig. 2). 


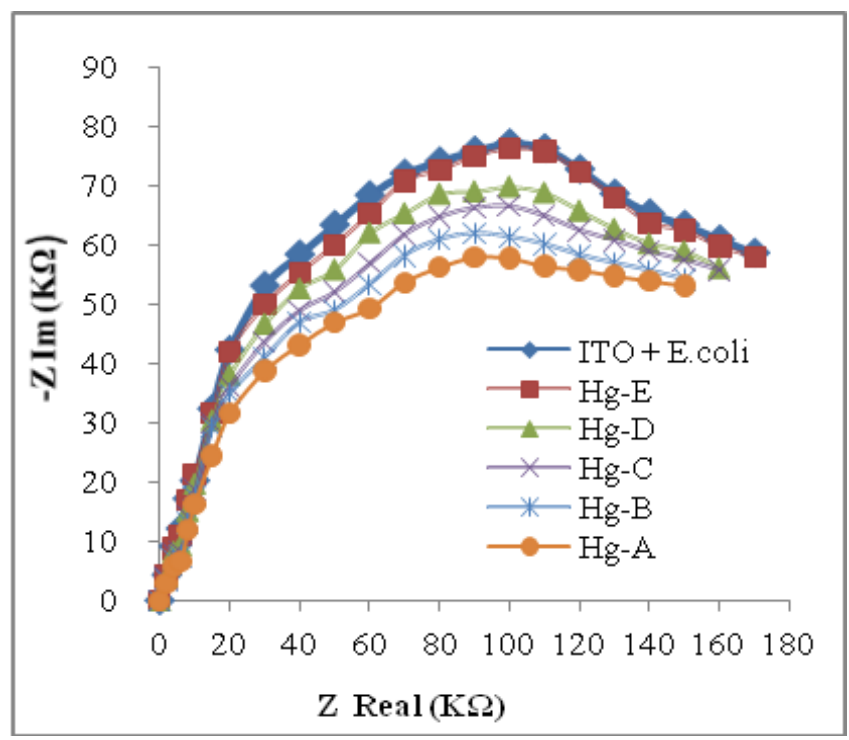

Fig. 1 Electrochemical impedance spectra for $\mathrm{Hg} 2+$ with (ITO-bacteria). $\mathrm{Hg}-\mathrm{A}$ : $\mathrm{Hg} 2+(10-4 \mathrm{M})$, Hg-B: Hg2+ (10-6 M), Hg-C: Hg2+ (10-8 M),

Hg-D: Hg2+ (10-10 M), Hg-E: Hg2+ (10-12M).

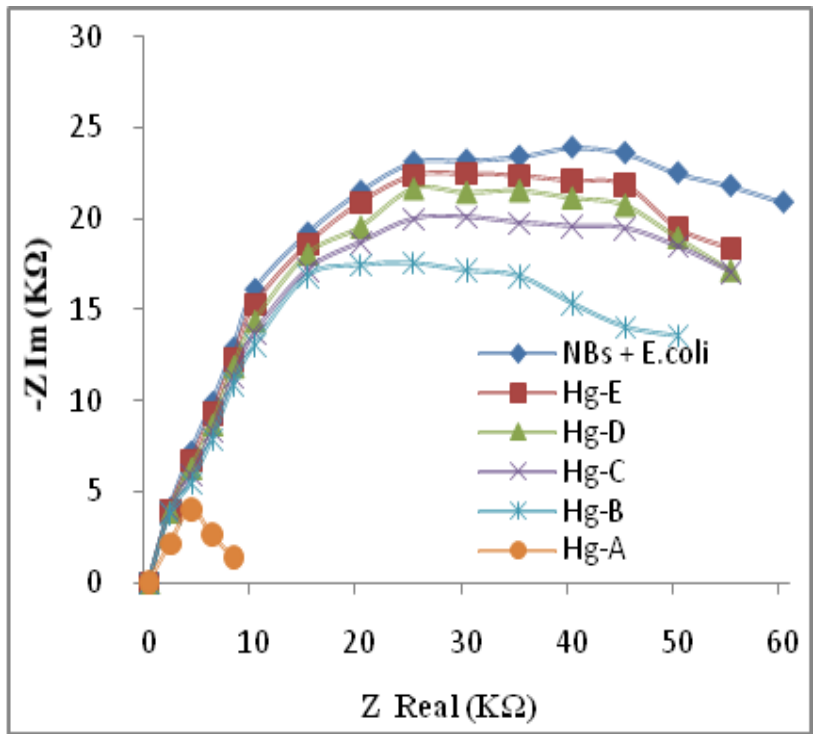

Fig. 2 Electrochemical impedance spectra for $\mathrm{Hg} 2+$ with (ITO-NBs-bacteria). $\mathrm{Hg}-\mathrm{A}: \mathrm{Hg} 2+(10-4 \mathrm{M})$,

Hg-B: Hg2+ (10-6 M), Hg-C: Hg2+ (10-8 M),

Hg-D: Hg2+ (10-10 M), Hg-E: Hg2+ (10-12M).

B. Impedimetric monitoring of bacteria deposited on ITO-(PEM)3-bacteria and ITO-NBs-(PEM)3-bacteria.

The impedance spectra of ITO-(PEM)3-bacteria and ITO-NBs-(PEM)3-bacteria was illustrated in in Fig. 3 and Fig. 4 with the concentrations varing from 10-12 $\mathrm{M}$ to $10-4 \mathrm{M}$. The results showed clearly that the detection limits of the two group were both 10-12 $\mathrm{M}$ when using immobilized polyelectrolytes with or without 
nanobeads. In addition, the recorded signal of ITO-NBs-(PEM)3-bacteria is a little higher when compared with the ITO-(PEM)3-bacteria group.

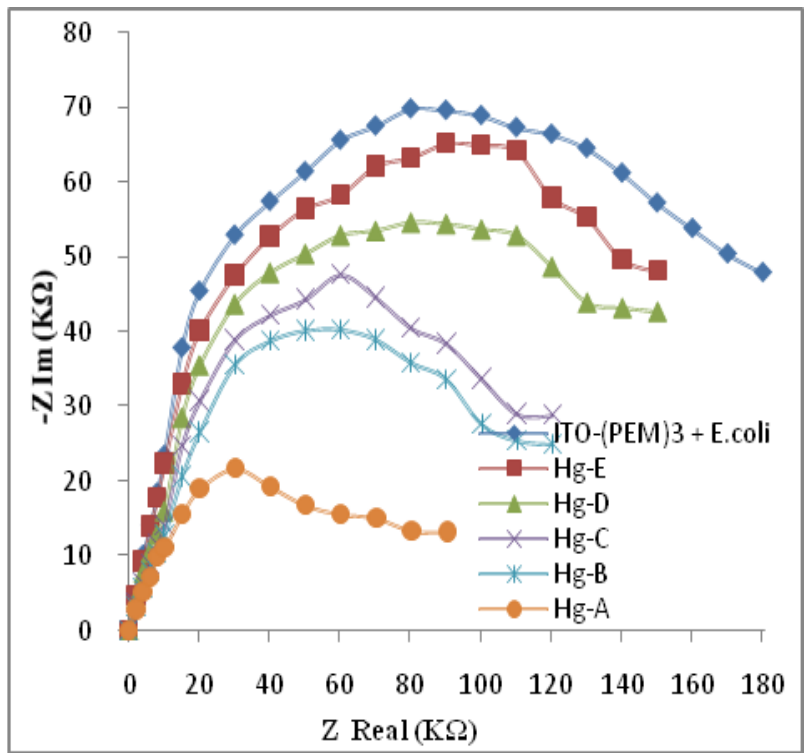

Fig. 3 Electrochemical impedance spectra for $\mathrm{Hg} 2+$ with (ITO-(PEM)3-bacteria). $\mathrm{Hg}-\mathrm{A}$ : $\mathrm{Hg} 2+(10-4 \mathrm{M})$, Hg-B: Hg2+ (10-6 M), Hg-C: Hg2+ (10-8 M),

Hg-D: Hg2+ (10-10 M), Hg-E: Hg2+ (10-12M).

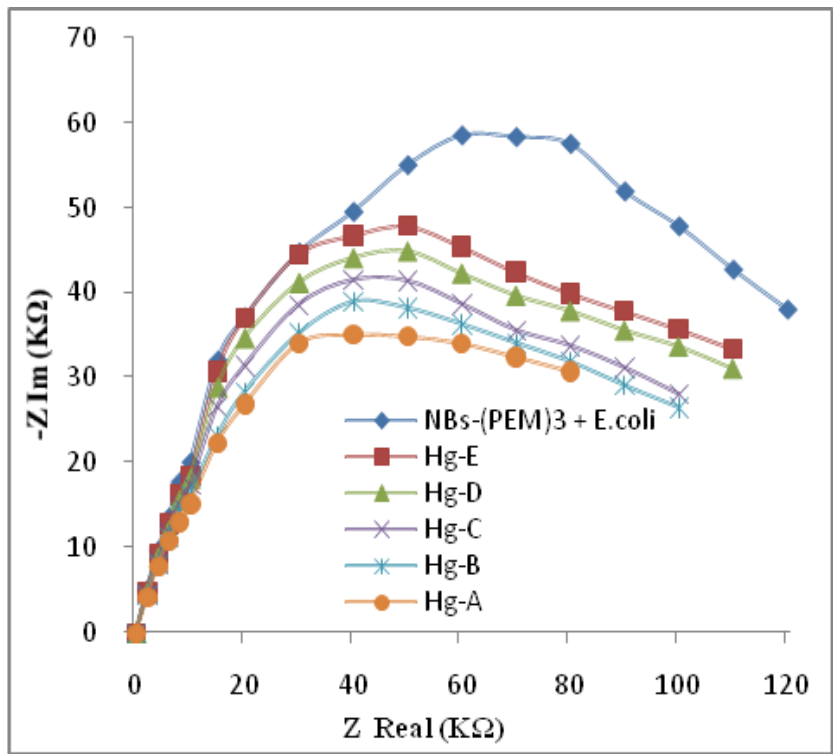

Fig. 4 Electrochemical impedance spectra for $\mathrm{Hg}^{2+}$ with (ITO-NBs-(PEM) $)_{3}$-bacteria). $\mathrm{Hg}-\mathrm{A}: \mathrm{Hg}^{2+}\left(10^{-4} \mathrm{M}\right)$, $\mathrm{Hg}-\mathrm{B}: \mathrm{Hg}^{2+}\left(10^{-6} \mathrm{M}\right), \mathrm{Hg}-\mathrm{C}: \mathrm{Hg}^{2+}\left(10^{-8} \mathrm{M}\right)$,

Hg-D: $\mathrm{Hg}^{2+}\left(10^{-10} \mathrm{M}\right), \mathrm{Hg}-\mathrm{E}: \mathrm{Hg}^{2+}\left(10^{-12} \mathrm{M}\right)$. 
The results indicated that changes in spectra reflect effects of heavy metal on the structure and function of E.coli cells. Heavy metal can change membrane capacitance as well as permittivity and conductivity of the cytoplasm. Dielectric spectroscopy of E.coli cell before and after exposure to heavy metals $\mathrm{Cd} 2+$, and $\mathrm{Cu} 2+$ was also investigated [6]. The same results were obtained.

\section{Conclusion}

Consequently, a cell biosensor which is based on the immobilization of bacteria E.coli magnetic nanobeads had been developed in order to detect the mercury. The nanobiocomposite film can provide a comfortable circumstance for the bacteria because it could exhibit large bacteria loading capacity and prohibit the leaching out of the immobilized bacteria. It is a better choice to utilize the resulted biosensor for detecting heavy metals effectively, exhibiting a good analytical performance and low detection limit compared to conventional methods.

\section{References}

[1] H. Abu Qdaisa and H. Moussab, "Removal of heavy metals from wastewater by membrane processes: a comparative study, " Desalination. USA, vol. 164, 2004, pp. 105-110.

[2] W.C. Leung, M.F. Wong, H. Chua, W. Lo and C.K. Leung, "Removal and recovery of heavy metals by bacteria isolated from activated sludge treating industrial effluents and municipal wastewater," Water Sci. Technol. Eng., vol. 41, (2000), pp. 233-240.

[3] S.I. Abu-Eishah, "Removal of $\mathrm{Zn}, \mathrm{Cd}$, and $\mathrm{Pb}$ ions from water by Sarooj clay," Appl. Clay Sci. vol. 42, 2008, pp. 201-205.

[4] J. J. Ackman and M. A. Seitz, "Methods of complex impedance measurements in biological tissues, " CRC Crit. Rev. Biomed. Eng., vol. 11, 1984, pp. 281-311.

[5] J. R. Macdonald, "Impedance Spectroscopy: Emphasizing Solid Materials and Systems," John Wiley \& Sons. NewYork. 1987, pp. 346.

[6] M. I. N. Zhang and J. M. H. Willison, "Electrical impedance analysis in plant tissues: A double shell model,” J. Exp. Bot. vol. 42, 1991, pp. 1465-1475. 